\title{
External Beam Radiotherapy \& Intracavitary Brachytherapy Is An Acceptable Treatment For Localy Advanced Carcinoma Of The Uterine Cervix
}

\author{
Md. Zillur Rahman Bhuiyan', Atiar Rahman', Sarwar Alam', Sheikh Saiful Islam Shaheen', Md. Ashadul Islam, \\ SK Golam Mostafa"
}

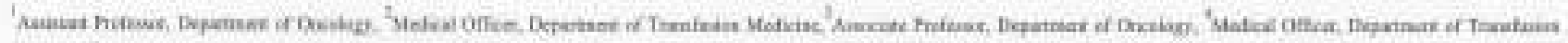

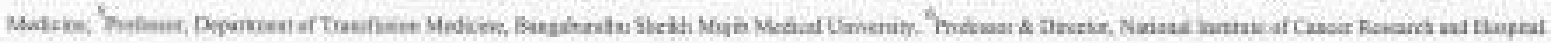

\begin{abstract}
:
Background: Cervical carcinoma is the second most common neoplasm in women worldwide and is the most frequent cancer among women in Bangladesh. In recent years, High Dose Rate (HDR) brachytherapy in combination with External Beam Radiotherapy (EBRT) has beea popular in the management of cancers of uterine cervix, Objectives: to evaluate the effectiveness and acute toxicity of fout fractions high dose rate intracavitary brachytherapy following pelvic external beam nadiotherapy in the treatment of locally advanced cervical carcinoma. Methods: Bangabandhu Sheikh Mujib Medical University \& NICRH chosen as a researcb place for EBRT and HDR brachytherapy. A typical radiotherupy treatment involves daily irradiation for several weeks. Whole pelvis was treated with total dose of $50 \mathrm{~Gy}$ in 5 weeks. Patients were treated once a day, 5 days a week with a daily fraction size of 2.0 Gy. EBRT: Pelvic radiotherapy dose is 50 Gy in 25 fractions (2.0 Gy per fraction) over 5 weeks. HDR brachytherupy dose is 7 Gy per fraction, total 4 fractions, each in a week over 4 weeks. Results: Ninety-eight patients were entered in the study. Three patients were excluded due to active non-malignant diseases. One patient had active tuberculosis, two patients had severe skin reactions and two patients withdrew following the first HDR application. The remaining Ninety patients were analyzed. Ninety patients completed the presenbed treatment and were evaluated. Eighty bad complete response with relief of symptoms, negative Pap-smear and no clinical signs of persistence disease at 3 months. Ten patients had a positive Pap-smear with clinical signs of persistence discase: Patients were evalunted before starting treatment with EBRT and before starting treatment with HDR ICBT. Conclusion: It can be casily concluded that 4 fractions of HDR ICBT, 7 Gy each weekly and pelvic EBRT can effectrvely and safely control locally advanced carcinoma of the uterine cervix. So that EBRT and HDR ICBT is an acceptable treatment for locally advanced carcinoma of the uterine cervix. Careful attention to normal tissue doses such as the rectum, bladder, and small bowel is important in the treatment of locally advanced cervical cancer.
\end{abstract}

Key words: External Beam Radiotherapy, High Dose Rate, Intracavitary Radiotherapy, Intracayitary Brachytherapy, National Institute of Cancer Research Hospital.

[BSMMUJ $2014 ; 7(1): 27-38$ ]

\section{Introduction :}

Carcianoma of the uterine cervix also known as cervical cancer is a malignant neoplasm of the cervix uteri or cervical area of the utenus in which the cells of the cervix becomes absormal and begin to grow uncontrollably.

Address for Correspondesce: Dr. Ma Zillu: Riàmas Bsuijan, Assivenet Prof.

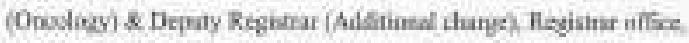

Racon a 223, Block-B, BSUMNU forming tumors'. Carcinoma of the uterine cervix is one of the more common cancers found in women. The cervix is the lowest most purt of the uterus, the part that protrudes into the top of the vagina. The cervix connects the uterus to the vagina.

Cervical cancer begins in the mucosal lining of the cervix uteri. Cervical cancer does not develop suddenly. Normal cervical cells gradually develop pre- cancerous changes 
that turn into cancer. Physician use several terms to describe these pre- cancerous changes, including dysplasia, squamous intracpithelial lesion (SIL) and cervical intraepithelial neoplasia (CIN). Only some women with pre-cancerous changes of the cervix will develop cancer. This process usually takes several years but sometimes can occur in less than a year. For most women, precancerous cells will remain unchanged and go away without any treatment. But if these pre- cancers are treated, almost all true cancers can be prevented?

Carcinoma of the uterine cervix or cervical cancer is the second most common neoplasm in wornen worldwide and is the most frequent cancer among women in Africa, Asia and South America'. It is the most common malignancy in South African black and colored females with a lifetime risk of 1 in 41 and the 2 nd and 5 th most common cancer in Asian and white females, respectively'. Carcinoma of the uterine cervix is accounting for $15 \%$ of all malignancies. The incidence and mortality rates vary between countries, the highest rates being recorded in the developing countries In Europe, variation between countries is higher in incidence than in mortality. In 2002 , age-standardized incidence rates varied between the lowest rate 4,3 per 100,000 people per years in Finland and the highest of 27.4 per 100,000 people per years in Serbia and Montenegro, Age-standardized mortality rates varied between 1.6 per 100,000 people per year in Malta and 13.0 per 100,000 people per year in Romanias. The global yearly incidence of cervical cancer for 2002 was 493,200 ; the annual death rate was $273,50 \times 0 \%$. It is estimated that in the year 2005 , there were about 520,000 cervical cancer cases in the world, of which 443,000 are in the developing countries. Over $80 \%$ of the cervical cancer presents at a fairly advanced stages with five year survival rates less than $40 \%$ ?

It is the must common cancer in women in developing countries, about $78 \%$ of cases occurning there, where cervical eancer is the most frequent cause of cancer death in women. Although the mean age of diagnosis is 52 years, carcinoma of the uterine cervix can be found in wonen between the ages of 17 and 90 years

Annual report 2005 based on bospital cancer registry in
National Institute of Cancer Research \& Hospital (NICRH), Dhaka stated that in Bangladesh mean age of presentation of carcinoma uterine cervix is 46.8 years where the range is 20 to 80 years and $38 \%$ of patients with carcinoma of uterine cervix in $40-49$ years age group, $21 \%$ patients in $50-59$ years age group and $17.3 \%$ patients in $30-39$ age group. Among whom about $53.8 \%$ were grand multipara and histopathology was revealed squamous cell carcinoma in about $94 \%$ of cases'.

In Bangladesh, though there is no available national based cancer registry but some hospital based cancer registry shows that each year 25000 women were diagnosed as carcinoma of the uterite cervix. Mortality is very high, nearly half of them died annually. Frequency of carcinoma of the uterine cervix from hospital based registry is $22-29 \%{ }^{10}$

A number of factors may influence the choice of local treatment for cervical cancer, including tumor size, stage, histologic features, evidence of lymph node metastasis, risk factors for complications of surgery or radiotherapy and patient preference ${ }^{\mathrm{H}}$. Treatment consists of surgery namely local excision in early stages and bysterectomy. In advanced stages, chemotherapy and radiotherapy are the treatments of choice. When advanced, it is often associated with high mortality and morbidity as the prognosis is very poor.

Patients with cervical carcinoma should be treated in elose collaboration with the gynecologic onoologist and the radiation oncologist, and an integrated team approach should be vigorously pursued ${ }^{12}$. Invasive cervical cancer may be treated by surgery, tadiotherapy, or a combination of both, with or without chemotherapy ${ }^{13}$.

Surgical treatment (radical hysterectomy) is effective management for early stages of cervical cancee. Cervical carcinoma is one of the malignancies that have been effec: tively treated with radiotherapy. Radiotherapy involves using ionizing radiation to kill cancer cells and can be used to treat early as well as late stages of cervical cancer Concurrent chemo-radiation should be considered in preference to radiation alone in the treatment of early stage carcinoma uterine cervix with poor prognostic 
factors after surgery and in the locally advanced cervical carcinoma. Chemotherapy is not used as a primary line of treatment for cervical cancer.

Radiotherapy (RT) plays a major role in the treatment of invasive uterine cervical carcinoma. Early invasive tumors are managed with either radical surgery or RT.

Locally advanced tumors are also treated with RT. Curative radiotherapy for carcinoma uterine cervix can be provided in two ways: intracavitary radiotherapy (ICRT) also known as brachytherapy and external beam radiotherapy (EBRT) also known as teletherapy either alone or in combination. Brachytherapy is a standard treatment in cervical cancer. Brachytherapy as monotherapy is an equally effective alternative to surgery in earlier stages. In more advanced stages, brachytherapy is used in combination with EBRT and often chemotherapy with use of cisplatin (collectively referred to as radio-chemotherapy). Brachytherapy delivers the increased doses of radiation needed to help prevent recurrence, without the increased toxicity, side effects and impaired quality of life associated with using higher doses of EBRT alone.

Optimal treatment results require a combination of dedicated planned EBRT and ICRT. The curative potential of radiotherapy in the management of carcinoma of the cervix is greatly enhanced by the use of brachytherapy. The success of brachytherapy may be attributed to the delivery of a high radiation dose to the tumor while sparing the surrounding normal tissues.

$\mathrm{RT}$ is the cornerstone and the treatment of choice for Federation International de Gynaecologic et Obstetrique (FIGO) stage IIB, IIIA, IIIB or IVA carcinoma of the cervix and is an excellent alternative to surgery in selected patients with stage IA, IB, or IIA diseases ${ }^{14}$.

RT for primary cervical cancer consists of a combination of EBRT and brachytherapy, except in the stage IA disease where brachytherapy alone may be used ${ }^{14}$. Ideally, pelvic radiotherapy begins with EBRT, which is designed to shrink the primary tumor and to improve the geometry for the brachytherapy insertions that follow.
Brachytherapy derieved from the Greek word 'brachos' which means short-range therapy. Brachytherapy is a radiotherapy treatment delivery system in which treatment of tumors is done by placement of radioactive sources in direct contact with the area of tumor. Modern radiotherapy techniques have focused on dose escalation to the target while reducing the dose to normal tissues. Brachytherapy can achieve both of these objectives in a highly conformal manner in a wide variety of disease sites.

Delivery of brachytherapy may be carried out at different dose rates, according to the International Commission on Radiation Units and Measurements (ICRU) 38 report, this are-

- Low Dose Rate (LDR): 0.4-2 Gy (Gray)/hour.

- Medium Dose Rate (MDR): 2-12 Gy/hour.

- High Dose Rate (HDR): 12-60 Gy/hour.

- Pulse dose rate (PDR): dose delivered in pulses over about a day (ICRU Report 38, 1985).

Both, LDR and HDR brachytherapy have been combined with EBRT.

LDR ICRT has a long history in the treatment of cervical cancer. The term "brachytherapy" refers to a strategy of implanting sealed radioactive sources either in close proximity to or in contact with the target tissue.

High-dose-rate (HDR) brachytherapy was initiated in the late 1950 s with a radiation source of Cobalt- 60 and has been increasingly used for the treatment of cervical cancer $^{12}$. The use of HDR brachytherapy is the result of technological developments in the manufacture of highintensity radioactive sources, sophisticated computerized remote after loading devices and treatment planning software. Several advantages of HDR brachytherapy, including rigid immobilization, outpatient treatment, patient convenience, accuracy of source and applicator positioning, individualized treatment with source optimization and complete radiation protection for personnel have been claimed ${ }^{15}$. These factors have promoted the outpatient management of HDR brachytherapy procedures and have increased the possible number of brachytherapy procedures that can be performed daily. Various HDR fractionation schedules have been used worldwide 
in different radiotherapy centers. The number of HDR brachytherapy fractions recommended by The American Brachytherapy Society (ABS) ${ }^{16}$ panel ranged from 4 to 8 ; but as proven and shown by some studies, even two fractions of HDR brachytherapy in addition to the EBRT are safe and effective in the management of this disease. HDR brachytherapy is an innovative form of internal radiation therapy used for the treatment of cervical cancer. Here, a precise, three-dimensional dose of radiation is delivered to the cervix. Computer guidance controls (1) how far the pellet goes into the applicator to precisely target the location of tumors, and (2) how long the pellet stays in the applicator to release its radiation dose. With a few well-placed catheters, HDR brachytherapy can provide a very precise targeted treatment for cervical cancer that takes only a few minutes ${ }^{17}$.

In recent years HDR brachytherapy with EBRT has become popular in the management of carcinoma of uterine cervix, because it eliminates many problems associated with LDR brachytherapy ${ }^{18,19}$.

Two main technique of irradiation, such as EBRT and brachytherapy in the form of ICRT are used for radical radiotherapy in the treatment of locally advanced cervical carcinoma. EBRT used to treat the whole pelvis and parametria including the common iliac and para-aortc lymphnodes, where as the central disease (cervix, vagina, medial parametria) is primarily irradiated with ICRT. In the context of definitive radiotherapy, limited disease is usually defined as disease primarily accessible by brachytherapy, whereas extended disease means that tumor extension and tumor volume will only allow brachytherapy after tumor shrinkage by external beam therapy.

The role of HDR ICRT and the total radiation dose delivered by EBRT and HDR ICRT including an appropriate fractionation schedule with associated acute toxicity for achieving complete response in the treatment of locally advanced carcinoma of the uterine cervix were evaluated in this study.

\section{Methods:}

This study employing a mixed method approach identified a number of factors that are associated with HDR brachytherapy treatment of cervical cancer. Patients were selected from Oncology department of Bangabandhu Sheikh Mujib Medical University \& NICRH for radiotherapy treatment by the qualified oncologist. Each patient was interviewed by the researcher himself and their particulars and history was documented according to prescribed data sheet. Clinical examination and necessary investigations were done. Clinical staging was done according to the FIGO stage grouping system.

All patients are clinically diagnosed and histologically proved carcinoma of uterine cervix, patient with locally advanced carcinoma of uterine cervix [clinical (FIGO) stage IIA (tumor more than $4 \mathrm{~cm}$ ) and clinical (FIGO) stage IIB-IVA cervical cancer], patient without distant metastasis and without obstructive feature. Patients are required to have ECOG performance status scale 0 up to 2 , age not more than 70 years, hemoglobin should be more than $10 \mathrm{gm} / \mathrm{dl}$ or more than $60 \%$, an absolute WBC count more than or equal to $4000 \mathrm{cell} / \mathrm{cmm}$, platelet count more than or equal to $100000 \mathrm{cell} / \mathrm{cmm}$, bilirubin level should be equal to or less than $1.5 \mathrm{mg} / \mathrm{dl}$, SGPT level not more than 4 times of the upper limit of normal, serum creatinine level should be equal to or less than 1.5 , blood urea level less than $50 \mathrm{mg} / \mathrm{dl}$.

Variables considered as age of the patient, socioeconomic condition, age of marriage, history of smoking, education, parity, history of post-coital spotting, history of intermenstural bleeding, vaginal discharge, pain in pelvis/hypogastrium, histopathology, FIGO stage of the disease at diagnosis, performance status, treatment response, toxicity.

Clinical assessment includes vaginal examination to inspect and palpate the extent of tumor in the cervix and vagina, and a bimanual examination to determine mobility and enlargement of the uterus. Vaginal spread is visualized using speculum, and rectal examination defines involvement of parametrial tissues, utero-sacral ligaments and fixation to pelvic sidewalls. EUA (Examination under anesthesia) ideally jointly with surgical colleagues and cervical biopsy, endocervical curettings and accurate assessment of the lesion according to the FIGO staging system was carried out in all patients. Cystoscopy was performed to look for invasion of the bladder base 
mucosa, and proctoscopy where rectal invasion was suspected. CT scanning of the abdomen and pelvis was performed for staging and assessing the renal tract and to detect ureteric obstruction or hydronephrosis, which may need stent placement prior to treatment.

The purpose of a radiotherapy treatment is to kill the tumor of a patient with ionizing radiation while sparing the surrounding healthy tissues as much as possible. A typical radiotherapy treatment involves daily irradiation for several weeks. A computed tomography (CT) scan was acquired before start of the treatment to visualize the anatomy, to delineate the tumor and the surrounding healthy tissues, and to define the target volumes needed for calculation of the radiation dose $\mathrm{e}^{20}$.

Whole pelvis was treated with total dose of 50 Gy in 5 weeks prescribed to the isocenter (or 100\%) where isocenter is defined as the intersection of 4 beams in a 4-field technique or midplane (and midline) for AP-PA. The goal is to keep prescription points consistent with previous trials. Four-field technique (AP-PA and lateral opposed fields) is recommended, particularly when treatment is delivered with a beam energy of $<15 \mathrm{MV}$. Patients were treated once a day, 5 days a week with a daily fraction size of 2.0 Gy. EBRT: Pelvic radiotherapy dose is 50 Gy in 25 fractions (2.0 Gy per fraction) over 5 weeks. HDR brachytherapy dose is $7 \mathrm{~Gy}$ per fraction, total 4 fractions, each in a week over 4 weeks. Desired cumulative (EBRT and ICRT) doses: Point A: total radiation dose is 85 Gy, Sidewall dose: total radiation dose is 54-60 Gy. Maximum doses to sensitive structures: Small Intestine: 60 Gy; Bladder: 80 Gy; Rectum: 70 Gy (RTOG 0417 protocol).

It was planned to start treatment with intracavitary HDR brachytherapy as early as at week two of completion of EBRT. When HDR brachytherapy begins, one insertion will be performed per week with no external beam therapy on the same day. Attempted to keep overall treatment time $<7$ weeks (56 days); prolongation of treatment time increases failure rate by $0.6 \%$ day in stage IB-IIA and by $0.9 \%$ /day in stage $\mathrm{IIB}^{21}$.

The following events were evaluated for treatment related toxicities: Nausea (Grade 0-III), Vomiting (Grade 0-IV),
Diarrhea (Grade 0-IV), Skin reaction (Grade 0-IV), Rectal toxicity (Grade 0-III), Urinary bladder toxicity (Grade 0-III), Leucopenia (Grade 0-IV), Anemia (Grade 0-IV).

\section{Results:}

Ninety-eight patients were enrolled in the study. Four patients were excluded due to active non-malignant diseases. One patient had active tuberculosis, two patients had severe skin reactions and one patients withdrew following the first HDR application. The remaining ninety four patients were analyzed.

The age of the patients under study were grouped in five segments (Table I). The ages of the patients were ranges from 28-67 years and mean age of the patients was 46.6 years. The peak age incidence of locally advanced carcinoma of the uterine cervix was found in the age group of $31-40$ years and $41-50$ years.

Table-I

Age of patients $(n=90)$

\begin{tabular}{lcc}
\hline Age group & Frequency & Percent \\
\hline 21-30 years & 03 & 3.33 \\
31-40 years & 34 & 37.78 \\
$41-50$ years & 27 & 30.00 \\
$51-60$ years & 17 & 18.89 \\
$61-70$ years & 09 & 10.00 \\
\hline
\end{tabular}

According to the report of house hold income and expenditure survey carried out by Bangladesh bureau of statistics division, ministry of planning, December 2000 and March 2003.

The distribution of selected patients participated in the study, according to their socio o economic status are displayed in Fig-1 and 2.

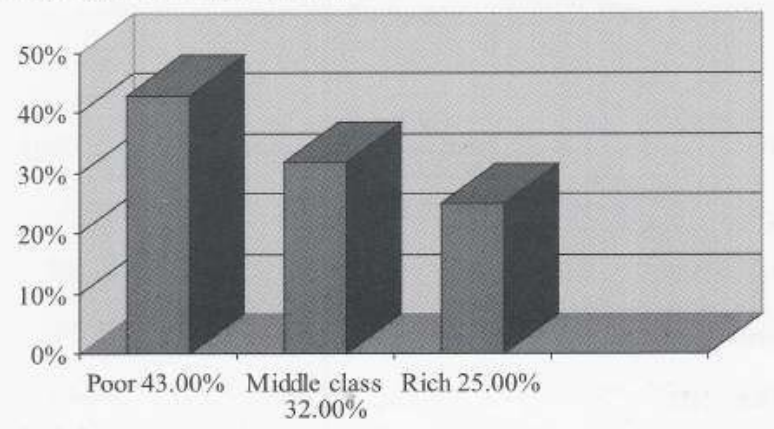

Fig-1: Distribution of patients according to the socioeco- 


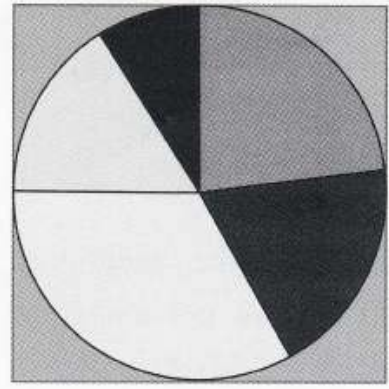

$\square$ Illiterate $23.00 \%$

Below primary $19.00 \%$

$\square$ Upto SSC $33.00 \%$

$\square \operatorname{HSC} 16.00 \%$

- Fraduate $0900 \%$

Fig-2: Distribution of patients according to educational qualification

\section{Patient on parity:}

It has been observed that maximum number of patients (73.33\%) participated in the study had given birth to 5-8 children (multiparous) (Table II).

Table-II

Parity of the patients participated in the study $(n=90)$

\begin{tabular}{ccc}
\hline Number of children & Frequency & Percent \\
\hline $1-4$ children & 17 & 18.89 \\
$5-8$ children & 66 & 73.33 \\
9 and more children & 07 & 7.78 \\
\hline
\end{tabular}

Table III married before the age of 20 years.

Table-III

Age of marriage of the patients $(n=90)$

\begin{tabular}{lll}
\hline Age of marriage & Frequency & Percent \\
\hline 11-20 years & 72 & 80.00 \\
21-30 years & 13 & 14.44 \\
$31-40$ years & 05 & 5.56 \\
\hline
\end{tabular}

Patients with FIGO stage of the disease at the time of diagnosis were tabulated in table-IV.

\section{Table-IV}

Patients with FIGO stage of the disease at the time of diagnosis $(n=90)$.

\begin{tabular}{lll}
\hline FIGO stage of the disease & Frequency & Percent \\
\hline Stage IIA (Tumor than $4 \mathrm{~cm}$ ) & 05 & 5.56 \\
Stage IIB & 44 & 48.89 \\
Stage IIIA & 28 & 31.11 \\
Stage IIIB & 13 & 14.44 \\
Stage IVA & 00 & 00.00 \\
\hline
\end{tabular}

Here the distribution of patients by FIGO stage of the disease, out of 90 patients with locally advanced carcinoma of uterine cervix selected for the study, four $(5.56 \%)$ were bulky (tumor more than $4 \mathrm{~cm}$ ) stage IIA, forty-four $(48.89 \%)$ were stage IIB, twenty-seven $(31.11 \%)$ were stage IIIA, thirteen (14.44\%) were stage IIIB and none $(0 \%)$ were stage IVA disease at the time of diagnosis.

\section{Table-V}

Results of Pap smear according to FIGO stage of the disease $(n=90)$

\begin{tabular}{lccc}
\hline $\begin{array}{l}\text { Stage of } \\
\text { Pap smear }\end{array}$ & $\begin{array}{c}\text { Number } \\
\text { of patients }\end{array}$ & $\begin{array}{c}\text { Negative } \\
\text { the disease }\end{array}$ & $\begin{array}{c}\text { Positive } \\
\text { Pap smear }\end{array}$ \\
\hline Stage IIA & 05 & 05 & 00 \\
Stage IIB & 45 & 41 & 04 \\
Stage IIIA & 27 & 23 & 04 \\
Stage IIIB & 13 & 11 & 02 \\
\hline
\end{tabular}

On evaluation of treatment response according to FIGO stage of the disease, 05 out of 05 patients $(100 \%)$ with bulky (tumor more than $4 \mathrm{~cm}$ ) stage IIA, 41 out of 45 patients $(91.11 \%)$ with stage IIB, 23 out of 27 patients $(85.19 \%)$ with stage IIIA and 11 out of 13 patients $(84.61 \%)$ had no clinical sign of disease and negative Pap-smear at 3 months time. that means achieved complete response and are displayed in Figure.

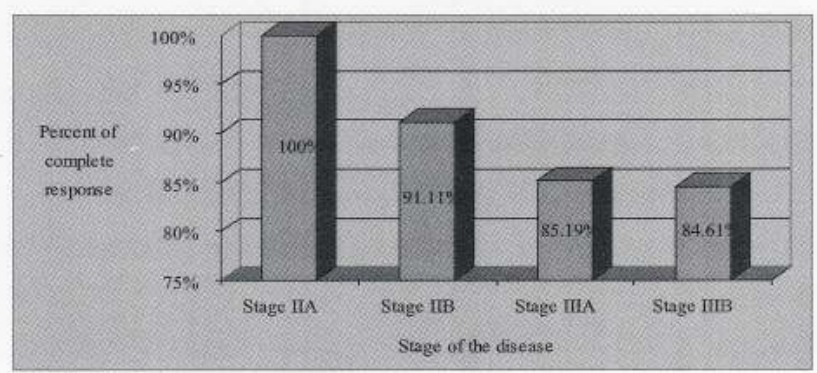

Fig-8: Distribution of patients according to response of treatment by FIGO stage of disease

There were 64 patients in the age group of 21-50 years, out of which $56(87.5 \%)$ and 26 patients were in the age group of 51-70 years, among which $22(84.62 \%)$ had no clinical sign of persistence disease and negative Pap-smear at 3 month follow up after completion of treatment $(\mathrm{p}=0.532)$. These results are tabulated in Table VI. 
Table-VI

Treatment response by age group $(n=90)$

\begin{tabular}{lccc}
\hline Age group & $\begin{array}{c}\text { Total number } \\
\text { of patients }\end{array}$ & $\begin{array}{c}\text { Negative } \\
\text { Pap-smear }\end{array}$ & $\begin{array}{c}\text { Positive } \\
\text { Pap-smear }\end{array}$ \\
\hline 21-50 years & 64 & 58 & 06 \\
51-70 years & 26 & 22 & 04 \\
$(\mathrm{p}=0.532)$ & & & \\
\hline
\end{tabular}

Table VII shows relationship between treatment response of tumor and number of fields. It have been observed that the number of fields used did not affect treatment response of tumor $(\mathrm{p}=0.603)$.

\section{Table-VII}

Relationship between treatment response and number of fields $(n=90)$

\begin{tabular}{lccc}
\hline $\begin{array}{l}\text { Number } \\
\text { of fields }\end{array}$ & $\begin{array}{c}\text { Number of } \\
\text { patients treated }\end{array}$ & $\begin{array}{c}\text { Negative } \\
\text { Pap-smear }\end{array}$ & $\begin{array}{c}\text { Positive } \\
\text { Pap-smear }\end{array}$ \\
\hline 2 & 65 & 58 & 07 \\
4 & 25 & 22 & 03 \\
$(\mathrm{p}=0.603)$ & & & \\
\hline
\end{tabular}

Table VIII shows relationship between duration of treatment and treatment response. Here we have observed that duration of treatment did not affect treatment response of tumor $(\mathrm{p}=0.402)$.

\section{Table-VIII}

Relationship between duration of treatment and local response of tumor

\begin{tabular}{lccc}
\hline $\begin{array}{l}\text { Duration } \\
\text { treatment }\end{array}$ & $\begin{array}{c}\text { Number of } \\
\text { patients treated }\end{array}$ & $\begin{array}{c}\text { Negative of } \\
\text { Pap-smear }\end{array}$ & $\begin{array}{c}\text { Positive } \\
\text { Pap-smear }\end{array}$ \\
\hline $48-56$ days & 73 & 67 & 07 \\
57-63 days & 17 & 13 & 03 \\
$(\mathrm{p}=0.402)$ & & & \\
\hline
\end{tabular}

Distribution of patients according to treatment response: In Table IX, patients were distributed according to treatment response, a complete response was observed in 80 out of $90(\mathrm{n}=90)$ patients $(88.89 \%)$ while partial response were observed in 10 out of $90(n=90)$ patients (11.11\%).

\section{Table-IX}

Distribution of patients according to treatment response $(n=90)$

\begin{tabular}{lcc}
\hline Treatment response & Frequency & Percent \\
\hline Complete response & 80 & 88.89 \\
Partial response & 10 & 11.11 \\
\hline
\end{tabular}

This study clearly demonstrates that four fractions, seven Gy in each fraction of HDR ICBT weekly and pelvic EBRT can achieved complete response in locally advanced carcinoma of the uterine cervix. Statistically highly significance $(\mathrm{P}<0.001)$ is observed in the study shown in Table $\mathrm{X}$ according to response pattern for total distribution of patients.

\section{Table-X}

Patients according to response pattern $(n=90)$

\begin{tabular}{lcccc}
\hline $\begin{array}{l}\text { Complete } \\
\text { response }\end{array}$ & Percent & $\begin{array}{c}\text { Partial } \\
\text { response }\end{array}$ & Percent & P Value \\
\hline 80 & 88.89 & 10 & 11.11 & $<0.001$ \\
\hline
\end{tabular}

\section{Associated toxicity of radiation treatment:}

The patients were assessed weekly during radiation treatment and six weekly after the completion of treatment for associated toxicity of radiation. Table 11 shows the hematological acute toxicities associated with radiation treatment during and after the treatment completion. Grade I nausea, vomiting, diarrhea and skin reaction were more prevalent among toxicities related to radiation treatment. Grade $0-2$ bladder and rectal toxicity were also associated with the prescribed radiation treatment. There was no interruption of treatment due to any severe toxicity. All observed toxicities were managed accordingly. 
Table-XI

Hematological acute radiation toxicities

\begin{tabular}{lcc}
\hline $\begin{array}{l}\text { Variables } \\
\text { Anemia }\end{array}$ & Frequency & Percent \\
\hline Grade I (Hb, 8-!0gm/dl) & 27 & 16 \\
Grade II (Hb. 6-8 gm/dl) & 30.00 & 17.78 \\
$\begin{array}{l}\text { Leucopenia } \\
\text { Grade I ( WBC 3000- }\end{array}$ & 28 & 33 \\
$4000 / \mathrm{cmm})$ & \\
$\begin{array}{l}\text { Grade II (WBC 2000- } \\
3000 / \mathrm{cmm})\end{array}$ & 31.11 & 36.67 \\
\hline
\end{tabular}

Table XII and Table XIII shows non-hematological acute toxicities associated with radiation therapy during after completion of treatment.

Table-XII

Non-hematological acute radiation toxicities

\begin{tabular}{lcc}
\hline Variables & Frequency & Percent \\
\hline Skin reaction & & \\
Grade 0 & 20 & 22.22 \\
Grade I & 22 & 36.67 \\
Grade II & 10 & 11.11 \\
& & \\
Diarrhea & & \\
Grade I & 32 & 35.56 \\
Grade II & 26 & 28.89 \\
& & \\
Vomiting & & 8.89 \\
Grade 0 & 08 & 26.67 \\
Grade I & 24 & 23.33 \\
Grade II & 21 & \\
Nausea & & 08.89 \\
Grade 0 & & 24.44 \\
Grade I & 08 & 14.44 \\
Grade II & 22 & \\
\hline
\end{tabular}

Radiation induced acute bladder and rectal toxicities were assessed and tabulated in Table-XIII.
Table-XIII

Radiation induced acute bladder and rectal toxicity

\begin{tabular}{lcc}
\hline Toxicity & Frequency & Percent \\
\hline Radiation induced & & \\
bladder toxicity & & \\
Grade 0 & 20 & 22.22 \\
Grade I & 15 & 16.67 \\
Grade II & 09 & 10.00
\end{tabular}

Radiation induced

rectal toxicity

$\begin{array}{lll}\text { Grade } 0 & 14 & 15.56\end{array}$

$\begin{array}{lll}\text { Grade I } & 08 & 08.89\end{array}$

Grade II $\quad 05 \quad 05.56$

These results from the quantitative and qualitative data will be discussed in the following chapter.

\section{Discussion :}

The ages of the patients in this study ranges from 27- 68 years. The peak age incidence of advanced cervical cancer was found in the age group of $30-50$ years $^{13}$ have published that the average age of cervical carcinoma is 50 but the study recorded that majority of the patients were in $30-50$ years of age group.

Regarding the risk factors, the findings of this study showed significant tendency towards early marriage, low socioeconomic status, first full term pregnancy before the age of 20, multiparity and unhealthy personal hygiene.

In this study, it was observed that more than $43 \%$ of the patients were from poor socio- economic background while $32 \%$ were from middle class background ${ }^{13}$. Bomfort C. K. et al. 2003 findings are in line with the study findings stating that "it is commoner in women of lower socioeconomic group."

In this study it had been observed that majority of patients were illiterate $(23 \%)$, below primary $(19 \%)$ and up to SSC level $(33 \%)$, which might have been a cause of low awareness about risk factors, screening and development of cervical carcinoma. 
Study revealed that majority of patients with cervical carcinsma were multiparous $(73.33 \%)$, the study also demonstrate that $80 \%$ of cervical cancer patient had history of early marriage (before the age of 20 years) and $84.09 \%$ of cervical cancer patients had history of her first full term pregnancy before the age of 20 years ${ }^{\text {n }}$ states that "This is thought to be due to the early age of the first intercoisset"

The analysis shows that a complete response was observed in 80 out of 90 patients $(88.89 \%)$ where as partial response was observed in 10 out of 90 patients (11.11\%)

It has been observed that the majority of treatment related acute radiation toxicities were grade I and grade II bladder and rectal toxicity along with Grade I nausea, vomiting, diamhea, skin reaction and Grade II eytopenias.

The findings in this study when compared to other studies that have been published, confirm that the use HDR and LDR ICBT for patients with cervical eancer result in similar treatment outcomes. Numerically, the study and all the other published data referred to in this study, sbow slightly higher figures for clinical outcomes with LDR compared to HDR ICBT, though statistical tests performed do not show any significant differences,

Despite screening programs, cervical carcinoma remains a major health problem throughout the world. Until recently, pelvic radiation has been the standard therapy for advanced disease with overall five-year survival rates of $50 \%$. Reoently, 5 randomized trials demonstrated a significant survival advantage for the concomitant administration of radiotherapy and cisplatin-based chemotherapy ${ }^{14}$.

Radiation therapy to eancer of the cervix is delivered with EBRT and ICBT. It is an alternative to surgery in stage I, IIA and comparable survival and tumor oontrol with either modality have been reported ${ }^{22}$. Scveral prognostic factors, including tumor stage, volume, age of patient, performance status, and presence of metastatic pelvic, paraaortic lymph nodes, have been shown to affect the therapeutic sutcome"t.
A variety of technical factors has been found to influence the morbidiry of radiation therapy in patients treated for carcinoma of the sterine cervix. Among these are the dose of irradiation, quality of the intracavitary insertion, type of application used and proportion of extemal beam or brachytherapy dose delivered. Host-related factors, such as the age of the patient, the presence of diabetes mellitus, hypertension, pelvic inflammatory discase and a bistory of prior surgery have also been reported to affect the incidence of complications ${ }^{2324}$.

Patients with extensive loco regional disease have a high rate of local relapse if treated surgically. For this reason, patients with stage IIB, III, and IVA tumors are treated with radiotherapy, which results in five-year survival rate of 65,40 , and less than 20 percent, respectively ${ }^{2}$.

In studies ${ }^{2}$ tumor saage was a marginally significant factor for five-year actuarial local control with $p$ value of 0.09. The treatment of FICO stage IIIB carcinoma of the cervix poses special problems for the radiation oncologist $t^{\text {. }}$. The tumor volume is usually large, and the likelihood of regional metastasis is high. As a result, clinicians tend to emphasize the role of EBRT more than they would for earlier stage diseases, arguing that an emphasis on ICRT results in relutive under treatment of the tumor extending toward or involving the pelvic sidewall, However, the results of a study done by Mark D. Logsdon und oolleagues ${ }^{2 n}$ provides convincing evidence that ICRT is a critical component of successful treatment of stage $11 \mathrm{BB}$ disease. In the literature, the survival and local control rate of stage II patients was better than that of stage III patients.

In the current study, 90 patients were analyzed, $5.56 \%$ of whom were stage IlA, while $48.89 \%$ of them were stage IIB, $31.11 \%$ were stage IIIA and $14.44 \%$ were stage IIIB disease. The response to treatment at 3 months was $100 \%$ in stage IIA, $91.11 \%$ in stage $11 \mathrm{~B}, 85.19 \%$ in stage IIIA and $84.61 \%$ in stage IIIB disease. The response to treatment was $91.67 \%$ vs. $85 \%$ for stage II and III disease respectively and the differences in treatment response among stages of the disease were statistically not significant $(\mathrm{p}=0.328)$. 
In the current study, the complete response rate based on 3 months clinical finding and Pap-smear result did not show any statistically significant differences when comparing the 4 fractions of HDR ICBT of 7 Gy each and EBRT and conventional LDR ICBT followed by EBRT.

According to a univariate analysis done in Brazil, the overall treatment time with cobort value of 50 days was a statistically significant fuctor for five years actuarial local control rute $(84 \% \text { versus } 53 \%, \mathrm{p}=0.008)^{2}$. The over-all treatment duration has been reported by several authors to be of prognostic significance in patients with cervical cancer treated by matiation therapy ${ }^{2121}$. The ABS $^{10,18}$ recoumends keeping the total treutment duration to less $t$ than 8 weeks because prolongation of total treatmient duration can adversely affect local control and survival ${ }^{27,2525}$. In this study, the duration of treatment did not influence significantly on complete response, but the follow up time is 500 sbort to assess definitively the ecmplete response as the response was assessed at 3 month.

In a study done by Robson Ferrigno and collages shows that patient's age with cohort value of fifty years did not influence the actuarial complete response $(p=0.99)^{23}$. In addition to that, this study has shown that complete response did not bave any dependency on age group of the patient and duration of treatment. The main reason why this study differs from others may be smull number of patients and very short follow up period.

In general, there is more variability in the rectal dose reports. As in some series, the point for calculation of the rectal dose is pre-determined and others take into account several points along the anterior rectal wall. In spite of the variatioas in the way the rectal doses are calculated, a cumulative dose of 75 Gy can result in a $10 \%$ incidence of proctosigmoiditis. With higher rectal doses, the incidence of proctosigmoiditis also increases ${ }^{203 i}$,

The study findings were described, discussed and compared with previously published relevant studies. The study objective was, how effectively and safely 4 fraction of HDR ICBT of $7 \mathrm{~Gy}$ each weekly and EBRT can control locally advanced carcinoma of uterine cervix. Though
L.DR ICBT is used conventionally but the advantages of HDR ICBT in terms of applicator rigidity, dose optimization, shorter treatment time, higher tum over of patients. out doxor based treatment delivery option, radiation safety of medical personnel involving in treatment delivery system make HDR ICBT a standard alternative to conventional LDR ICBT. There ane also some disadvantages of HDR ICBT like bigh set up cost, short half life of radioisotope souroe, necessity of highly trained medienl personnel make HDR ICBT lese popular in BT treatment delivery system but HDR ICBT is appropriate in center especiatly where high number of patients with cervical cancer requining the brachytherapy service.

Considering all these advantages and diadvantages, this study revealed that 4 fractions of HDR ICBT of 7 Gy each weekly and EBRT can effectively and safely achieve. complete response in locally advanced carcinoma of the uterine cervix.

\section{Conclusion :}

The result of this study suggests that EBRT and HDR ICBT is an acceptable treatment for locally axtvanced carcinoma of the uterine eervix Careful attention to normal tissue doses such as the rectum, bladder, and small bowel is important in the treatment of locally advanced cervical cancer

Due to some potentiat advantages of HDR-ICBT, such as rigid immobilization, outpatient treatment, patient convenience, accaracy of source and applicator positioning, individualized treatment with souroe optimization and complete radiation protection for personncl, HDRICBT should be considered a standard treatment strategy for patients with cervical cancer instead of LDR-ICBT, especially in developing countries, where high number of patients with cervical cancer requiring the bracbytherapy service.

Limiting the number of HDR bracbytherapy application may improve patient comfort und compliance. 4 insertions of 7 Gy each HDR application was feasible with an acceptable conplication rates and equivalent local control 
rates when compared with conventional LDR 1CBT.

In the subgroup analysis there was no significant difference between HDR and LDR ICBT when considering Iocal control me and treatment reluted acute complications for patients with locally advanced carcisoma of the uterine cervix.

It can be easily conclused that 4 fractions of HDR ICBT, 7 Gy each weekly and pelvic EBRT can effectively and safely control locally advanced cascinoma of the uterine cervix.

\section{References:}

1. Kamar V, Abbac AK, Fasto N \& Mackell R 2007, Rebtrins Bawe Pathology \{8th ed.), Saimden Flswien, Sylney.

2. Amersan Cabcer Society web sate, 2012 atailable at hute: www. cancersorgencentervical eancer.

3. Morris M, Eifed PJ, Griesby PW, Lu J. Levenback C. Stevens RE 1999, 'Pelvis Katision with Coocurrent Charosthicropy Compored with Pelvie and Panaanrtic Patiution for Highrixs Cervicat Canoer', 1990; 340:1137-1143.

Sittas F \& Madhoo I 1998. Cancer statistics in Sauth Africa.

4. Insidence of Hisdolagical Diagnoses of Cnncer 1993-1995. Notionat Canoer Repissury of South Africa. Institute of Medical Reseasch. $1 \mathrm{H}$

1ARC 2607, Imternatwaal Agency for Reseanch on Cancer and

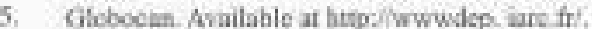

Fetuy 3, Bnay F, Pisani P, S Parkin D, 'Glahal eancer statistaiss

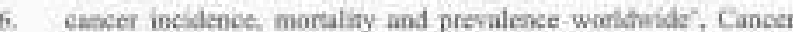

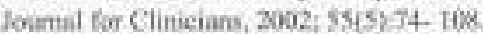

Ssekatanurayman R, Btack RE, Pakis DM (Eds) 199k, Cancer

7. survial it developing esontries. Iyon: LARC Press. CARR: Scieteife Putblisations No. 14 9

Ruhin P. Willams JP (odv) 2001, Clencal Oncology. A Maltidisei-

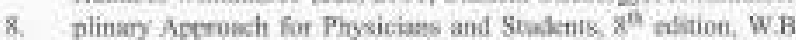
Sanders Concony, $433-478$.

Talukdar H, Jabemn S, Staheen S, Inlam J, Ksrim N, Alam AMMS

9. 2005, Hoipilal based cancer regisery in Banglabesh, Annual report, 1:12-13

Mabh KJ 2010, Recent mansgement of cervical saneer, $22^{\text {nd }}$

10. AGM and Scientific seminar-2010 (2011, Fehnary 5). Bangledesh cancer society. 36

DeVita VT If Lawremce IS, Resenberg SA (eds) 2008, Devita,

11. Hellmun \& Rusenbers's Cancer: Prinkiples \& Practice of Oncology, s $^{\text {h }}$ editian, Lippincot Willimens \& Wilkims, $+2: 2$

Hefoerin EC, Parez CA, Braby LW (eds) 200s, Perez and Braity's
12. Principles and Practice of Onodasy, $y^{\text {ts }}$ edition, Lippincot Williams \& Witkins, 1532-1609

Bousford CK \& Kunkler :H (eds) 20K1:, Walter and Miller's

13. Texibouk of Radiotherapy, $6^{\circ}$ editian. Charchil Livingstone. $465-477$

Daenas-Giverteiez A, Cetifa L, Mariscal h and Garza J. Aodent

14. Management of Loeally Advanced Cervical Carcinouma Cancer Truatmens Reviews 7003:29:389-349

Judith AS, Jack FE, Brues RT, Dolones AB, Bhudast PF and

15. Timodty JR, HDR Intacavitory Bruchysterapy for Carcinoma of Cenvix: The Madison System li Ctinical and Radiological Coessid. cration", Intemutional foenal of Radatios Oocology Biol. Pbys $1997,24: 335-348$

Nog 5. Fricksun B. Thumadwen B, Ohten S, Demases ID and

16. Petereit D. The Ameticin Bracliytherapy Society Resimsenendatices fur High-Doos-Raiv Brikbyberapy for Carcinemia of the Cervix'. Intermational krumal Radiation Oneslogy Biol. Phyd. $2000 ; 48(1): 201-211$

RTOG 0417, thin probocol was dosizoed und developed by the

17. Rautiatiun Therany Onoolvgy Croup (RTOE) of the Amerisant Colloge af Ratiolngy (ACR).

Wane C., Leung SW, Coen BC, Sun LM, Fang FM, Changehien

1月. CC Hunig EY. Wu JM and Clum CC 1097, High Dase Rase Intracanitary Iinchytherapy in the Trentmint of Uscrine Cern Canper, 5-years results and implicatiun of incteased bow-grade ractal complication an initiation of an HDR-IC fracticesation

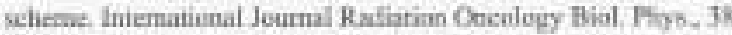
(2) $391-398$

Nar S, Oron C, Youmy D, and Erickson B'The Anterican Brachy-

14. therapy Socicty Sarvery of Brachytherapy Practice for Carcinuma of the Cervix in United States: Gymaccolony ancology 1099 73: $111-118$

FCUU Repont 50 1999, Inismatizal Cammission of Radiation

29. Untrs and Meseurement. Prescrihing recording and reporting phowos beam therapy (semplensent to ICRE Repor 50) November Ioge. XIR $\{$ i 2

Frie KH, Roxch M III (ed) 2110, Handbook of Evideres Hased

21. Radiation Onabory, $2^{\text {st }}$ editive. Spainger Science \& Business Media, LLV zota $490-511$

Toita T, Moromizato H Ogawa K. Katimokan $Y$, Machama T,

32. Kanasawa K and Muirnama S, Coecuremt Csemo Radiotherupy Usine Hipk-Dosc-Rate intrasaviary lerachytherapy foc Lierine Cervical Cancer, Gyrsecology Slucology 2005; 96065-670

Stehmm FB, Bundy BN, Disais PJ, Key HM, Larson. JE and

23. Fowler WC 1991, Carcinuma of Cervix Tresement whth Radiatian Therapy 1. A multi-variase malysis of proghoolic sanables in ise 90G, Cancer 63 (11):2776-2785.

Perez CA, Grighty PW, Lockutt MA. Clifford Clau KS and

24. Williamann J. 'Radliation Morbidity in Cancinoma of the Ulerise Cervia Dosimeter and Clinical Carroction', International Joumal Radiation Docology Bjol. Pays., 1999; 44:855-866.

Maia MP, Fogarnlli RC, Gentil AC and Saljoli JY 2001 , High

25. Doese Hare Brachutherapy in the Treatment of Uterine Cervical Comeer. Anulysis of door Eflectiveness and Lese Complicutions'. 
International Sonat Retatkon Oncology Biol. Phys., $5015 \times 1123-1135$

Logsdan MD and Eifel P3, FIGO Stago UIB squamous cell carcinousa of the pervixi. An Analysis of The Propgostie Factor

26. Fimphasining the Balance Between Fxocrnal Bean and Intracavitary Radiation Therapy', Intemational Journal Radiacion Oncology Bul. Phys, 1999, 43:363-735.

Ner D, Dasan N ind Allhright RM, Gynaccologie Brachytherapy 1: Froper Intorporation of Brachythurapy into the Carresh

27. Multimodality Manngement of Carciocan of the Cervix. Seninars in Radraticn Oncology, 2001; 12(1): 40-52

Grinsky T, Rey A, Roche B, Haic C, Gertaulet A, Randriasarivello $H$, and Chaseagne D, Overall treatuent time in advanced

28. cervical varcisocar. A critical parancter in treatment onitoros: Imemntional Journal Radiation Oncolagy Brol, Plyys 1994; 27:105!-1056.
Pelereit DG, Sirkaria JN \& Potter DM, Schink JC, High dase rwe Nersus for dose rate brachytherapy in the treatment of cervical

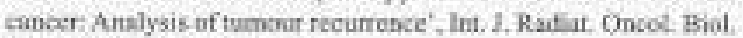
29 Pbys, 1999; 45:1267-1274.

Pmy 11, Dunckkanp I, Littrand B, Momex F, Bentier J, Gonzales-Gonzaies D, Late Effest-of Toxidity Seoring: SOMA Scale, Oscolong Bial. Phys.,31(3):1043 - 104 ?

30

Rockke JC, Mundt AJ, Halpen H, Sweeney P, Suttoe H, Powers C. L.ate rectal sequelae following definitive radiaties therapy for carcinuma of the uterine cervic: A desimetric analyals, Rucation Biol, Thys, 1997; 37:351-358. 